\title{
Pemanfaatan Tanaman Enceng Gondok Sebagai Peluang Usaha Kerajinan Anyaman Di Kelurahan Kebraon Karangpilang Surabaya
}

\author{
Juliani Pudjowati*1,Susi Tri Wahyuni*2, Novelita Nur Afifah*3, Brillian Ayu Cahyaning Safi'i ${ }^{* 4}$, \\ Kharisma Masithah Kabarudin*5 \\ 1,2,3,4,5 Program Studi Ekonomi Pembangunan, Fakultas Ekonomi dan Bisnis, Universitas Bhayangkara \\ Suarabaya, Indonesia \\ *e-mail: juliani@ubhara.ac.id ${ }^{1}$
}

\begin{abstract}
Abstrak
Alasan pengabdian masyarakat dikarenakan banyak tanaman Enceng gondok tumbuh masif dan subur kurang dimanfaatkan sehingga perlu pendampingan agar tumbuhan ini mempunyai nilai tambah bagi masyarakat terutama peningkatan pendapatan. Salah satu lokasi tempat pertumbuhan enceng gondok yang sangat berlimpah yakni di daerah Kebraon, Kecamatan Karangpilang, Kota Surabaya, pada kegiatan ini diperkenalkan bahwa tanaman enceng gondok tersebut dijadikan sebuah kerajinan anyaman yang bermanfaat sebagai peluang usaha untuk alternatif menambah pendapatan. Metode yang digunakan Pelatihan. dan diskusi serta difusi teknologi pengolahan serat enceng gondok. Proses pengolahan yaitu: proses, Membuat pola, Proses menganyaman, Proses menyulam, Membuat handel, menjahit, Finishing . Kesimpulan dengan adanya pengabdian masyarakat pelatihan enceng gondok dapat mengurangi dampak negative dari keberadaan enceng gondok yang dapat mengurangi kadar oksigen didalam perairan. Serta memberdayakan masyarakat sekitar yakni bertugas untuk menganyam kerajinan tersebut. Selain itu, lingkup pemasaran juga semakin luas terbukti dari adanya pesanan kerajinan eceng gondok tidak hanya dari dalam kota saja tetapi dari luar kota bahkan sampai luar negeri.
\end{abstract}

Kata kunci: Enceng Gondok, Peluang Usaha, Kebraon Karangpilang

\begin{abstract}
The reason for community service is that many of the water hyacinth plants grow massively and are underutilized so they need assistance so that these plants have added value for the community, especially increased income. One of the locations where water hyacinth is very abundant is in the Kebraon area, Karangpilang District, Surabaya City. In this activity it was introduced that the water hyacinth plant is used as a woven craft which is useful as a business opportunity for alternative income generation. The method used in community service with knowledge, training. and discussion and technology diffusion of water hyacinth fiber processing. The processing processes are: the process, making the pattern, the process of weaving, the process of embroidering, making handles, sewing, finishing. The conclusion is that the existence of community service water hyacinth training can reduce the negative impact of the presence of water hyacinth which can reduce oxygen levels in the waters. As well as empowering the surrounding community, namely in charge of weaving these crafts. In addition, the marketing scope is also getting wider, as evidenced by the existence of water hyacinth handicraft orders not only from within the city but from outside the city and even abroad.
\end{abstract}

Keywords: Enceng Gondok, Business Opportunity, Kebraon Karangpilang

\section{PENDAHULUAN}

Selama ini enceng gondok dianggap sebagai tanaman yang banyak memberikan kerugian dikarenakan enceng gondok mempunyai kecepatan berkembang biak vegetative yang sangat cepat dan tidak terkendali, terutama di daerah tropis dan subtropics, sehingga banyak perairan, khususnya perairan air tawar menjadi tertutup oleh enceng gondok [1]. Tanaman ini berasal dari Brazilia dan pertama kali didatangkan ke Indonesia lewat Kebun Raya Bogor pada tahun 1894. sebagai tanaman pengganggu. Sekarang eceng gondok adalah gulma dan merusak lingkungan perairan. Penelitian menyebutkan dalam dua bulan mampu tumbuh hingga satu meter persegi. Untuk mengatasi pertumbuhan dan penyebaran eceng gondok yang relatif masif, maka berbagai cara dilakukan supaya tanaman ini dapat dimanfaatkan menjadi produk bernilai ekonomi. [2][4].

Awalnya merupakan tanaman hias yang digandrungi karena bunganya yang berwarna ungu sangat menarik sebagai penghias kolam seperti Teratai. Namun akibat pertumbuhannya 
yang sangat cepat dan tak terkendali, hal itulah yang menyebabkan enceng gondok sangat potensial pemanfaatannya [5]. Salah satu lokasi tempat pertumbuhan enceng gondok yang sangat berlimpah yakni di daerah Kebraon, Kecamatan Karangpilang, Kota Surabaya, Provinsi Jawa Timur. Jenis Tanaman Eceng gondok hidup mengapung di air menghasilkan serat dengan kualitas yang baik dan kadang-kadang berakar dalam lumpur. Tingginya sekitar 0,4-0,8 meter. [4], [6].

Menurut [4], tentang membuat briket dengan campuran enceng gondok (Euchornia crassipes) yang sebelumnya sudah dipirolisa menjadi arang, dengan dua jenis perekat, yaitu tepung terigu dan tepung tapioca. Hasil penelitian memperlihatkan bahwa briket dengan bahan perekat tepung tapioka lebih baik daripada briket dengan bahan perekat tepung terigu. Briket dengan perekat tapioka memiliki shatter index dengan loss yang paling sedikit serta stability yang lebih baik, meskipun nilai kalornya sedikit dibawah nilai kalor briket dengan perekat terigu [4].

Menurut [7], Hasil yang didapat dari kegiatan pengabdian ini adalah kegiatan berlangsung dengan baik di mana kelompok tani Desa Buahan sangat antusias dengan kegiatan ini yang ditunjukkan dengan rata-rata kehadiran anggota kelompok petani adalah 63\%. Pupuk organic eceng gondok yang dihasilkan memenuhi syarat baku mutu kompos. Pemanfaatan eceng gondok yang merupakan gulma danau untuk pupuk organic di Desa Buahan, kecamatan Kintamani, Bangli akan sangat bermanfaat untuk peningkatan pendapatan petani disamping juga untuk menjaga kelestarian Danau Batur[7].

\section{METODE}

Pelaksanaan kegiatan Abdimas ini adalah memberdayakan masyarakat di wilayah Kebaron kelurahan Karangpilang untuk memperoleh penghasilan keluarga dengan membuka peluang usaha kerajinan ayaman enceng gondok yang diikuti oleh 30 ibu-ibu PKK di Kebraon. Kegiatan ini dilakukan dengan pengetahuan, pelatihan. dan diskusi serta difusi teknologi pengolahan serat enceng gondok sehingga menghasilkan sebuah produk anyaman yang cantik. Kuisioner dilakukan sebelum dan sesudah penyampaian materi. Kuisioner setelah penyampaian materi merupakan evaluasi mengenai peningkatan pemahaman dan minat masyarakat dalam pemanfaatan tanaman enceng gondok untuk peluang usaha. Evaluasi juga dilakukan setelah penyampaian materi untuk mengetahui peningkatan pemahaman dan minat masyarakat terhadap pemanfaatan tanaman tanaman enceng gondok untuk peluang usaha. Adapun proses pengolahan enceng akan dijabarkan pada gambar 1 :

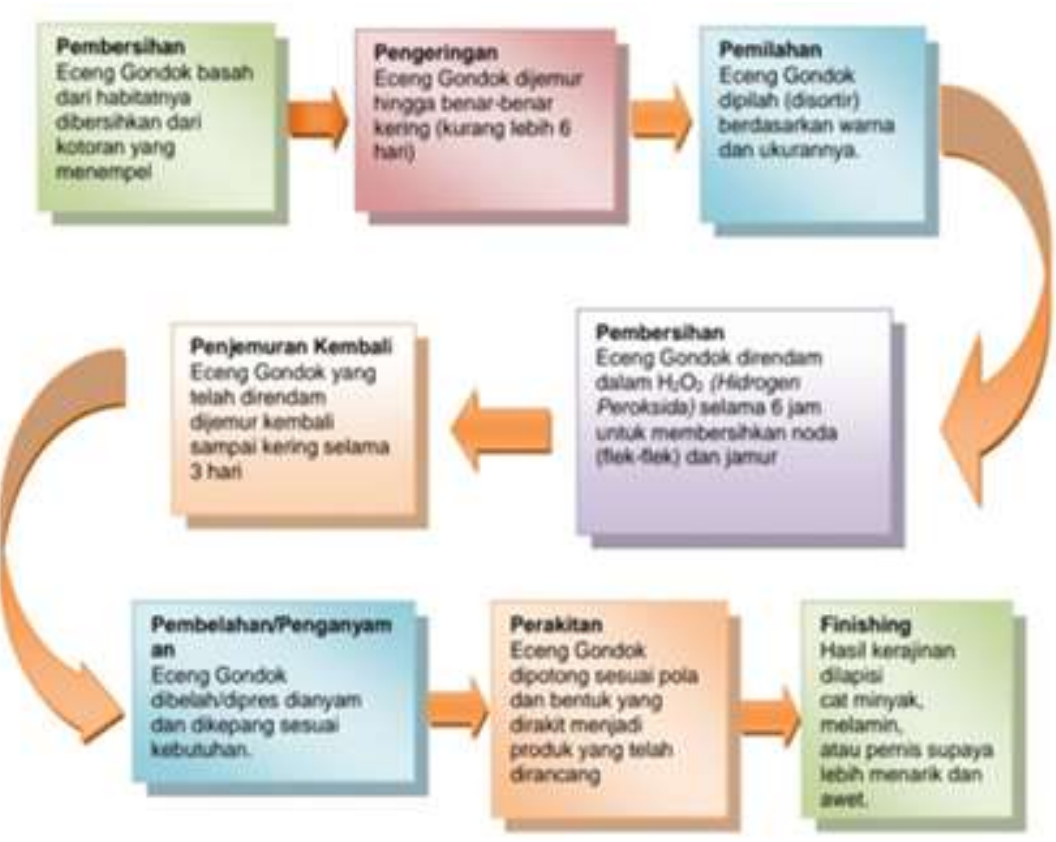




\section{Gambar 1: Prosedur Pengolahan Enceng Gondok}

Gambar 1 dapat dijelaskan sebagai berikut :

a. Proses ini merupakan proses awal untuk membuat kerajinan enceng gondok yaitu dengan mengambil tanaman enceng gondok yang kemudian dilakukan proses pengeringan selama 1 minggu sampai 25 hari tergantung cuaca, setiap tenaman enceng gondok yang sudah kering masih dipilih dikelompokan berdasarkan ukuran karena ada yang tanaman besar dan kecil. Hal ini bertujuan agar saat proses penganyaman tidak memilih-milih lagi bentuknya karena sudah dikelompokan sesuai ukuran dan ketebalan.

b. Membuat pola.

Proses selanjutnya adalah membuat pola misalnya membuat pola tas maka dilakukan pemotongan kayu bisa dari triplek yang kemudian dibuat sesuai keinginan atau pesanan tas. Kayu tadi susun atau dirangkai dengan menggunakan palu kecil yang biasanya bentuknya kotak atau bulat.

c. Proses menganyaman.

Setelah dilakukan pembuatan pola tahap selanjutnya ialah dengan menganyam dengan pola yang telah dibuat. Pola tadi digunakan saat menganyam enceng gondok tadi menjadi berbentuk dan bisa sama ukurannya dengan yang lainnya.

d. Proses menyulam.

Setelah dilakukan proses menganyaman proses selanjutnya yang dilakukan penyulaman. Proses ini cukup lumayan sulit karena memerlukan kesabaran dan ketelatenan. Hal ini bertujuan karena pola yang sudah dibuat harusdi sulam dengan warna dan bentuk yang sama. Dalam proses ini menyulam menggunakan benang, pita dan variasi lainya, tingkat kesulitapun bergantung pada volume barang yang akan di sulam, lama nya waktu pengerjaan dalam menyulam satu barang tas kecil misalnya bisa dikerjakan satu orang 1 hari karena itu butuh keahlian khusus dalam proses ini.

e. Membuat handel.

Proses ini adalah pembuatan handel atau gantungan pada tas -tas karena proses ini menggunakan gunting atau alat pemotong lainya untuk digunakan sebagai tali pada tas.

f. Pemotongan.

Tahap proses pemotongan ini yaitu memotong busa yang digunakan sebagai lapisan tas bagian dalam, bagian dalam tas yang bertujuan lebih bagus, lebih rapat dan bervolume. Pemotongan busa mengikuti bentuk dan pola tas yang akan dibuat.

g. Menjahit.

Tahapan selanjutnya setelah pemotongan adalah menjahit bagian dalam tas yang berisi busa dan kain kemudian dijahit sebagai lapisan dalam tas agar lebih rapat aman dan bervolume, dan lebih menarik. Dalam menjahit bagian dalam lapisan dalam tas ini menggunakan tangan tanpa mesin jahit, kecuali saat pemasangan resleting bagian tas yang ada resletingnya.

h. Finishing.

Tahapan terakhir setelah kerajinan enceng gondok hampir sempurna , maka dilakukan proses finishing. Proses finishing dilakukan untuk memperindah kerajinan enceng gondok yang telah dibuat sehingga sesuai keinginan konsumen di pasaran.

\section{HASIL DAN PEMBAHASAN}

Kegiatan pengabdian pada masyarakat yang berjudul pemanfaatan tanaman Enceng Gondok sebagai peluang usaha anyaman di Kelurahan Kebraon Karang Pilang Surabaya pada hari Sabtu 25 Januari 2020. Kegiatan pengabdian ini diikuti oleh ibu-ibu rumah tangga yang tergabung dalam kelompok PKK. Pada Kegiatan ini telah diberikan penjelasan tentang bagaimana pembuatan bahan serat enceng gondok menjadi suatu macam-macam produk, untuk pengelolahannya enceng gondok memang membutuhkan waktu yang cukup lama sekitar 25 hari 
untuk pemipihan atau pengeringan. Kemudian baru dibuat sebuah pola yang diinginkan atau sesuai permintaan.

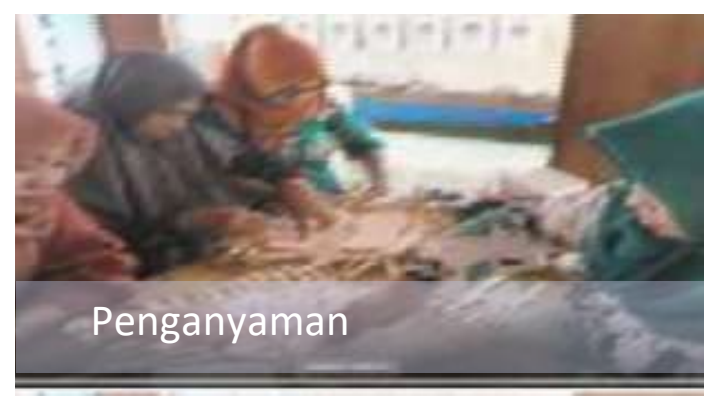

Gambar 2. Kegiatan penganyaman membuat produk jadi

Gambar 2, proses penyulaman membutuhkan ketelatenan dan kesabaran, dengan tujuan bahwa pola yang telah dibuat disulam sesuai dengan warna dan bentuk harus sama. Proses menyulam menggunakan benang, pita dan variasi lainnya tergantung selera. Tingkat kesulitan juga tergantung jumlah dan bentuk gambar pola. Setiap orang mengerjakan satu produk yang dibuat supaya terjaga kualitasnya.

kegiatan ini awal mula bahan diperoleh lebih mudah karena melimpahnya akan tanaman enceng gondok yang ada di waduk kedurus/kebraon. Untuk mengurangi populasi tanaman enceng gondok yang dapat merusak ekosistem sungai, menjadi sebuah pemikiran, bagaimana ya enceng gondok itu sendiri bisa dimanfaatkan dan dikelola menjadi sesuatu kerajinan yang mempunyai nilai jual tinggi dan tentunya produk yang sangat unik.

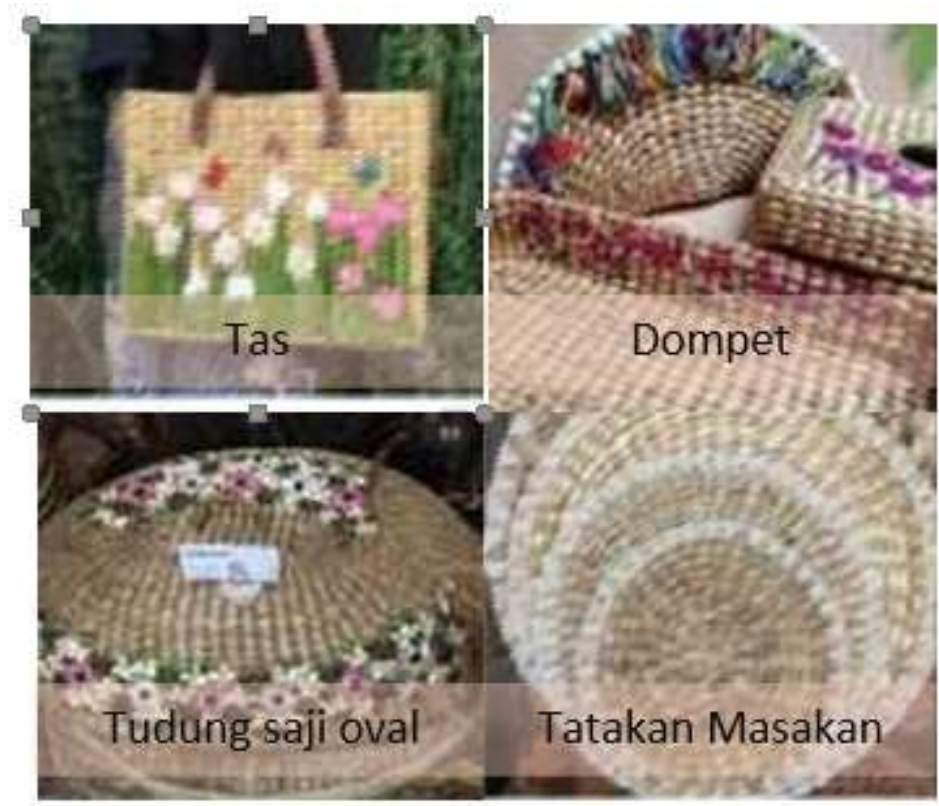

Gambar 3. Hasil Kerajinan Produk Ayaman Enceng Gondok

Pada gambar 3 , keberadaan enceng gondok dan produk kerajinan yang ramah lingkungan, Produk kerajinan enceng gondok merupakan produk ramah lingkungan karena dalam proses pembuatannya tidak menggunakan bahan kimia yang dapat membahayakan kesehatan dan lingkungan. Pada proses pengecatan tidak menggunakan suatu zat yang aman untuk lingkungan. Hal itu dilakukan untuk membuat tampilan produk menjadi lebih mengkilap dan lebih indah. Semula keberadaan enceng gondok di wilayah perairan waduk Kebraon dapat merugikan lalulintas air karena waduk tersebut biasanya dimanfaatkan untuk olah raga jetsky. Enceng gondok akan menghalangi jalannya jetsky sehingga olah raga tersebut tidak bisa berjalan lancar, 
namun pada akhirnya enceng gondok membawa manfaat bagi lingkungan dengan memberdayakan masyarakatnya dengan kegiatan pelatihan diselenggarakan di balai desa setempat yang peserta paling banyak berasal dari kalangan ibu rumah tangga. Alasannya adalah untuk memberdayakan ibu rumah tangga yang dapat memiliki jiwa wirausaha, kreatif, dan produktif. Penyuluhan yang dilaksanakan juga dibantu oleh istri sang pemilik Bu Wiwit, dimana beliau ikut memberikan bimbingan mengenai cara mengolah enceng gondok, menganyam, menyulam, membuat model barang yang akan dibuat serta dan yang lainnya. Banyak ibu rumah tangga yang turut serta membantu pembuatan kerajinan tangan enceng gondok. Dengan adanya hal tersebut Quality Control dilakukan bersamaan dengan proses pembuatan kerajinan tangan yang dibuat oleh para ibu rumah tangga atau ibu-ibu PKK di Kebraon.

\section{KESIMPULAN}

Lingkungan dan masyarakat yang memanfaatkan Enceng Gondok menjadi kerajinan tangan berupa tas, sepatu, sandal, tudung saji, tatakan masakan, karpet, rompi, topi, kursi dan sebagainya. Ditinjau dari aspek sains yakni mengurangi dampak negative dari keberadaan enceng gondok yang dapat mengurangi kadar oksigen didalam perairan. Dari aspek lingkungan yang dimiliki oleh yaitu dapat mengurangi keberadaan enceng gondok yang memiliki dampak negative bagi lingkungan apabila tetap dibiarkan tumbuh liar, selain itu produk yang digunakan dalam pembuatan kerajinan enceng gondok tidak menggunakan bahan kimia sehingga merupakan produk yang ramah lingkungan dan tidak berbahaya. Dalam aspek masyarakat, usaha ini memberdayakan masyarakat sekitar yakni bertugas untuk menganyam kerajinan tersebut. Selain itu, lingkup pemasaran juga semakin luas terbukti dari adanya pesanan kerajinan eceng gondok tidak hanya dari dalam kota saja tetapi dari luar kota bahkan sampai luar negeri.

\section{UCAPAN TERIMA KASIH}

Terima kasih kepada:

1. Universitas Bhayangkara Suarabaya yang telah memberi dukungan financial terhadap pengabdian masyarakat ini.

2. Ibu-ibu PKK dilingkungan perumahan Kebraon yang telah berpartisipasi pada pengabdian ini

3. Bu Wiwit, Pemilik usaha kerajinan enceng gondok yang telah ikut memberikan bimbingan mengenai cara mengolah enceng gondok.

\section{DAFTAR PUSTAKA}

[1] S. Suryono, "IbM Pemanfaatan Enceng Gondok Dan Jerami Sebagai Pakan Ternak Dan Pupuk Alternatif Di Desa Ngargorejo," PRIMA J. Community Empower. Serv., 2017, doi: 10.20961/prima.v1i1.35149.

[2] R. A. Retnoningrum, "Pemanfaatan Enceng Gondok Sebagai Produk Kerajinan: Studi Kasus di KUPP Karya Muda 'Syarina Production' Desa Kebondowo Kecamatan Banyubiru," Journal of Visual Arts. 2014.

[3] J. Tangio, "Pemanfaatan Biomassa Enceng Gondok Dari Danau Limboto Sebagai Penghasil Biogas," Jambura J. Chem., 2019, doi: 10.34312/jambchem.v1i1.2105.

[4] N. Utomo, Arif Fajar, Primastuti, "Pemanfaatan limbah furniture enceng gondok," J. Teknol. Kim. dan Ind., 2013.

[5] A. Nugroho, A. F. Daru, and W. Adhiwibowo, "Pengembangan Pemasaran Online Usaha Kerajinan Enceng Gondok dan Pandan di Desa Lopait Kecamatan Tuntang Kabupaten Semarang," J. Transform., 2014, doi: 10.26623/transformatika.v12i1.87. 
[6] A. F. Utomo and N. Primastuti, "Pemanfaatan Limbah Furniture Enceng Gondok (Eichornia crassipes) di Koen Gallery sebagai Bahan Dasar Pembuatan Briket Bioarang," J. Teknol. Kim. dan Ind., 2013.

[7] N. L. M. Pradnyawathi and N. L. Kartini, "PENGOLAHAN ECENG GONDOK (Eichhornia crassipes) UNTUK PENINGKATAN PENDAPATAN MASYARAKAT DAN PELESTARIAN DANAU BATUR DI DESA BUAHAN KECAMATAN KINTAMANI KABUPATEN BANGLI PROPINSI BALI," Bul. Udayana Mengabdi, 2019, doi: 10.24843/bum.2019.v18.i01.p10. 